\title{
0 exercício dos papéis parentais na guarda compartilhada
}

\author{
The exercise of parental roles in shared custody
}

Amanda Pansard Alves ${ }^{[0]}$, Dorian Mônica Arpininib], Sabrina Daiana Cúnico ${ }^{[c]}$

\footnotetext{
${ }^{\text {[a] }}$ Mestranda em psicologia pela Universidade Federal de Santa Maria, Santa Maria, RS - Brasil, e-mail:

amanda.pansard@hotmail.com

${ }^{[b]}$ Doutora em psicologia, professora da Universidade Federal de Santa Maria, Santa Maria, RS - Brasil, e-mail: monica.arpini@gmail.com

${ }^{[c]}$ Doutoranda em psicologia pela Pontifícia Universidade Católica do Rio Grande do Sul, Porto Alegre, RS - Brasil, e-mail: sabrinacunico@yahoo.com.br
}

\section{Resumo}

Esta pesquisa buscou conhecer como pais e mães estão vivenciando a experiência da guarda compartilhada dos seus filhos. Para tanto, integraram este estudo três mães e dois pais que estabeleceram a guarda conjunta dos filhos por meio de um acordo realizado em um Núcleo de Assistência Judiciária de uma instituição federal de ensino superior. A pesquisa teve caráter qualitativo e foi realizada com o uso da técnica de entrevistas semidirigidas de questões abertas. Os resultados alcançados apontam que mesmo estando estabelecida a guarda compartilhada, a mãe permaneceu como a principal figura responsável pelos filhos, sendo a família extensa uma grande fonte de ajuda e apoio a essas famílias. Além disso, o estabelecimento de um novo relacionamento por parte do pai ou da mãe pode configurar um obstáculo para o exercício das funções paterna/materna. Por fim, identificou-se a necessidade de espaços que promovam o fortalecimento das relações paterno-filiais após a separação.

Palavras-chave: Custódia da criança. Relações familiares. Guarda compartilhada. Parentalidade.

\section{Abstract}

This research aimed to discover how parents are living the experience of shared custody of their children. In order to do that, three mothers and two fathers who established shared custody of their children through an agreement carried out in a Legal Aid Center of a federal institution of higher education participated in the study. The research was qualitative and was carried out using the semi-directed interviews technique with open questions. The results achieved show that even though shared custody was established, the mother remained the main figure responsible for the children, being the extended family an important source of help and support to these families. In addition, the establishment of a new relationship by the father or mother can set up an obstacle to the exercise of parental functions. Lastly, the need for spaces that promote the strengthening of the relationships between father and child after separation was identified.

Keywords: Child custody. Family. Family relations. Shared custody. Parenthood. 


\section{Introdução}

O modelo de família nuclear surgiu juntamente com a ascensão da burguesia no século XIX, onde passou a ser valorizado o âmbito privado - ligado à reprodução - em oposição ao âmbito público - ligado à produção. Nessa época, os homens passaram a se dedicar à produtividade, ou seja, à vida pública, e as mulheres voltaram-se ao âmbito doméstico, dedicando-se, principalmente, ao cuidado com os filhos, trabalho anteriormente destinado às serviçais (Badinter, 1985; Reis, 2010).

É nesse período, também, que um novo ideal de casamento se constitui: a família fundada no amor romântico, na qual a formação do laço conjugal passou a se dar pela escolha do parceiro, sendo o casamento o lócus da reciprocidade dos sentimentos e dos desejos carnais (Féres-Carneiro, 1998; Roudinesco, 2003). Com a ascensão da medicina social, os indivíduos foram incentivados a exercer os papéis de pais e mães de família. 0 pai, entendido como mais forte, seria responsável pela autoridade familiar e pelo provimento dela, e a mãe, considerada mais sensível e delicada, ficaria encarregada pela criação dos filhos e pelo cuidado da casa (Brito, 2005; Grisard Filho, 2009; Reis, 2010).

Tal estrutura familiar coloca a mãe num lugar de maior importância no contexto familiar, uma vez que atribui a ela certo poder na esfera doméstica, por outro lado, o pai, considerado como o chefe da família, exercia a "posse" dos filhos e da esposa. Segundo Reis (2010), essa concepção moderna de família surgiu inicialmente nas camadas burguesas, estendendo-se, posteriormente, para todas as classes sociais. Pode-se dizer que a família moderna representa um momento de acentuação das diferenças entre homens e mulheres, estabelecendo a divisão dos direitos e deveres de cada um (Reis, 2010).

Conforme visto, por muito tempo, os papéis masculino e feminino foram bem demarcados no âmbito familiar. Hoje, entende-se que a autoridade parental ou responsabilidade parental, antes denominado pátrio poder, é, de acordo com Grisard Filho (2009), "o conjunto de faculdades encomendadas aos pais, como instituição protetora da menoridade, com o fim de lograr o pleno desenvolvimento e a formação integral dos filhos, física, mental, moral, espiritual e social" (p.35). Na redação original do Código Civil de 1916, quem exercia esta autoridade era somente o pai - visto como o chefe do casamento - ficando a mãe excluída deste contexto (Brito, 2005; Grisard Filho, 2009).

Essa configuração familiar, com os papéis do homem e da mulher bem definidos, passou a não funcionar bem a partir da segunda metade do século passado. As mudanças começaram a surgir com a inserção das mulheres no mercado de trabalho, com o surgimento dos movimentos feministas e a maior facilidade ao divórcio (Grisard Filho, 2009; Pereira, 2011). Tais mudanças refletiram nas decisões judiciais e nas propostas de reformulação do Código Civil (Brandão, 2005; Pereira, 2011).

Em 1962, através da Lei ${ }^{\circ} 4.121$, é conferida à mãe a condição de colaboradora do pai no exercício do poder parental, deixando de ser exclusividade do homem a decisão sobre a prole e o patrimônio (Brandão, 2005; Grisard Filho, 2009). Somente em 1977 , com a Lei $n^{\circ} 6.515$, fica indicado claramente que ambos os genitores são os titulares dos encargos parentais (Grisard Filho, 2009). Também na Constituição Federal, em seu artigo 226, parágrafo 5 o, é descrito que "os direitos e deveres referentes à sociedade conjugal são exercidos igualmente pelo homem e pela mulher" (Brasil, 1988).

Além de ser entendido hoje que o poder familiar deve ser exercido regularmente por ambos os pais, ele é compreendido como um poder-dever. Constitui uma obrigação, já que o que existe é uma responsabilidade dos pais em relação ao filho (Grisard Filho, 2009; Simão, 2005). 0 poder justifica-se apenas objetivando o êxito dos deveres. Assim, é ultrapassada a ideia do filho como um objeto/propriedade do pai, para se transformar em um filho-sujeito, titular de direitos (Ramos, 2005).

Segundo Grisard Filho (2009), o poder familiar é efeito da paternidade/maternidade, e não do matrimônio ou da união estável, conforme é descrito no Código Civil em seu artigo 1.632: "A separação judicial, o divórcio e a dissolução da união estável não alteram as relações entre pais e filhos senão quanto ao direito, que aos primeiros cabe, de terem em sua companhia os segundos" (Brasil, 2002).

Dessa forma, mesmo após a separação conjugal, o pai e a mãe continuam detentores desta autoridade familiar. No entanto, para Silva (2005), a guarda no modelo exclusivo está associada à percepção de que as mães são as únicas capazes de cuidar dos filhos e que, de acordo com Badinter (1985), é um mito construído culturalmente, não podendo ser 
compreendido como algo da natureza feminina. Também, observa-se que, ainda hoje, as custódias de filhos no Brasil, em sua grande maioria, são destinadas unilateralmente às mães, conforme dados do Instituto Brasileiro de Geografia e Estatística ${ }^{1}$ (IBGE, 2010). Assim, podemos verificar a persistência da crença de que a mãe é a única possível cuidadora dos filhos, sendo este entendimento partilhado por pais e mães, como também pelo poder judiciário (Badinter, 1993; Bottoli \& Arpini, 2011).

Além disso, em uma pesquisa empreendida por Brito (2005), foi verificado que $70 \%$ dos pais e mães entrevistados que estavam separados reconhecem que o genitor que não detém a guarda dos filhos participa bem menos das decisões importantes relacionadas a eles. Pode-se observar, nesse sentido, que ao genitor não-guardião é destinado um papel secundário, privando-o do integral relacionamento com seu filho, passando este modelo de guarda a ser questionada em diversos âmbitos (Grisard Filho, 2009). Além disso, destaca-se hoje uma nova postura adotada por uma parcela de pais, no sentido de desejar e exercer uma paternidade mais atuante e responsável (Bottoli \& Arpini, 2011; Silva \& Piccinini, 2007), mesmo após o rompimento conjugal.

Diante das críticas direcionadas ao modelo exclusivo de guarda e da conjunção entre o princípio da igualdade e o princípio do melhor interesse da criança, surge a guarda compartilhada como uma alternativa para garantir o convívio de ambos os genitores com seus filhos, como também a possibilidade de equilibrar o exercício dos papéis parentais após a separação (Brito, 2005; Cardoso, 2008; Grisard Filho, 2009; Pereira, 2005).

A guarda compartilhada é recente no ordenamento jurídico brasileiro, tendo sua sanção em 2008 através da Lei $n^{\circ} 11.698$ que institui e disciplina esta modalidade de guarda, embora que sob o aspecto constitucional ela já pudesse ser aplicada (Pereira, 2011). Em outros países, no entanto, ela já vigora há mais tempo, um exemplo é a Suécia, onde está presente há mais de 30 anos (Brito 2005; Grisard Filho 2005). Segundo citado na redação da lei supracitada, este modelo prevê a responsabilização conjunta dos genitores (Brasil, 2008). De acordo com Grisard

1 Em 87,29 dos casos, as mães são detentoras unilateralmente pela guarda dos filhos. (IBGE, 2010)
Filho (2009), "o modelo da nova lei preserva o pleno exercício do poder familiar, sem esvaziar as funções paterna e materna ou eliminar os referenciais masculino e feminino, assegurando aos filhos um equilibrado desenvolvimento emocional, psíquico e social" (p. 192-193).

A partir desta análise, e com o objetivo de conhecer como é o exercício dos papéis parentais na guarda compartilhada dos filhos, este estudo tem por finalidade apresentar um recorte da pesquisa intitulada "Reflexões sobre a guarda compartilhada: o olhar de pais que a vivenciam" (Alves, 2012). Tal pesquisa teve por objetivo conhecer como é a vivência de pais e mães que tenham acordado o modelo compartilhado de guarda dos filhos em comum.

\section{Método}

\section{Participantes}

Fizeram parte deste estudo três mães (M) e dois pais (P) que estabeleceram a guarda compartilhada dos filhos, mediante acordos realizados em um Núcleo de Assistência Judiciária Gratuita de uma instituição pública de ensino superior. Foram incluídos pais e mães que estavam vivenciando a guarda compartilhada por pelo menos um ano, excluindo-se as demais situações. A partir deste critério de inclusão, foram integrados no estudo todos os pais e mães que aceitaram participar da pesquisa. No Quadro I, encontram-se as demais informações referentes a cada participante.

\section{Instrumento}

A pesquisa teve caráter qualitativo e foi realizada através de entrevistas semi-dirigidas de questões abertas. Este modelo se caracteriza por um encontro interpessoal entre entrevistador e entrevistado, onde o primeiro é o responsável pelo encontro e o segundo é um convidado a expressar suas opiniões (Turato, 2003). A coleta de informações, de acordo com o autor, é baseada no discurso livre do entrevistado através da introdução de tópicos pelo entrevistador, facilitando, dessa forma, a coleta de dados. 
Procedimentos

Inicialmente, o estudo previa que as entrevistas fossem realizadas conjuntamente com pais e mães que tivessem estabelecido em acordo a guarda compartilhada do(s) filho(s). No entanto, ao realizar os contatos por telefone, muitos dos possíveis sujeitos da pesquisa não aceitaram realizar a entrevista em conjunto com o (a) ex-companheiro (a). Assim, o procedimento foi alterado para que as entrevistas fossem realizadas individualmente, com as mães e os pais em separado, não necessariamente um ex-casal.

Todos os participantes, antes da entrevista, foram esclarecidos sobre os objetivos do estudo, bem como o compromisso com a confidencialidade da identidade dos sujeitos por parte do pesquisador, recebendo um termo de consentimento livre e esclarecido que assinaram e autorizaram a sua participação nesta pesquisa. As entrevistas foram realizadas nas dependências da instituição de ensino a qual a pesquisadora está vinculada, em sala adequada.

Além disso, o estudo está respaldado nas Diretrizes e Normas Regulamentadoras de Pesquisa envolvendo Seres Humanos (Resolução 196/96 do Conselho Nacional de Saúde) e na Resolução n ${ }^{\circ}$ 016/2000 do Conselho Federal de Psicologia, sendo aprovada a realização da pesquisa pelo Comitê de Ética de uma universidade pública de ensino superior, sob o número 03926312.4.0000.5346.

\section{Análise dos dados}

Após a realização das cinco entrevistas, que foram gravadas, realizou-se a transcrição na íntegra para posterior análise dos dados. A análise foi qualitativa, utilizando-se a análise de conteúdo de Bardin (1977). Foi realizada a leitura e a análise individual de cada entrevista transcrita, onde foram identificados os aspectos referentes à temática proposta no estudo de cada uma delas. Em seguida, foram identificados os aspectos comuns entre as falas dos entrevistados e realizou-se o agrupamento destes temas em tópicos, que foram elencados em categorias, a fim de promover o melhor entendimento acerca dos dados obtidos. Com a obtenção das categorias, foi possível fazer uma correlação entre a teoria acerca do tema e os dados obtidos nas entrevistas.

\section{Resultados e discussão}

Os resultados deste estudo serão apresentados em três categorias, que são: 1 . A parentalidade na guarda compartilhada; 2 . A entrada de um terceiro; 3. Rede de apoio: o lugar da família extensa na guarda compartilhada.

\section{A parentalidade na guarda compartilhada}

Diversas autoras (Brito, 2002; Féres-Carneiro, 1998; Sousa 2010) apontam para a necessidade de que seja feita uma diferenciação entre a conjugalidade e a parentalidade no momento da separação. É necessário pontuar que o casal que passa a não existir após a dissolução da união é o conjugal; já o parental deveria continuar existindo, mantendo-se com o dever de prover afetiva e materialmente a prole (Féres-Carneiro, 1998; Pereira, 2011). Neste contexto, pode-se observar, através da fala do participante (P2), que o diálogo entre os pais, após a separação, foi mantido, proporcionando uma manutenção do exercício das funções parentais por ambos os genitores.

A gente se dá tão bem hoje que assim ó, só não deu certo eu e ela junto entendeu?! Mas hoje assim, eu considero ela assim como uma das minhas melhores amigas, assim digamos né. Daí então, eu acho que nós não teríamos um bom relacionamento, tão estreito assim como a gente tem hoje. Entendeu?! Pelo fato da gente ter que tá brigando, coisa que não seria necessário. (...) Então é tudo assim eu, a mãe dele e ele tá sempre assim, em tudo que diz respeito a ele [referindo-se ao filho] a gente tá sempre em comum acordo, sempre conversa bastante sabe?! (P2)

Ao definir a guarda compartilhada, busca-se conservar a coparticipação dos pais na formação dos filhos, mantendo o exercício efetivo do poder familiar (Madaleno, 2012; Pereira, 2011). Neste sentido, uma das mães participantes do estudo (M3), expõe, no seu entendimento, como deve ser a manutenção dos vínculos paterno-filiais após a separação:

pai é pai e mãe é mãe, isso não tem separação, (...) não é por que a gente se separou que tu vai deixar de ser mãe ou ele vai deixar de ser pai, ou que tu vai 
deixar de amar um filho, eu acho que isso vai continuar pra sempre, eu né, na minha opinião. Independente de eu ter ou não ter outro companheiro. (M3)

De acordo com a participante a relação apenas se transforma, assinalando que "não vai deixar de ser mãe ou ele vai deixar de ser pai". É possível constatar que ela consegue diferenciar estas duas relações conjugalidade e parentalidade. Também, é possível observar que para esta participante (M3), os afetos em relação ao filho, permanecem os mesmos, indicando que "isso vai continuar pra sempre". No entanto, Sousa (2010), assinala que a diferenciação entre o casal conjugal e o casal parental, em muitos casos, demanda tempo, já que a construção destes vínculos é um processo lento.

0 exercício conjunto da guarda surge, também, como um dispositivo que tem por objetivo reforçar os sentimentos de responsabilidade do genitor que não habita com a criança (Brandão, 2005). Pode-se constatar, a partir da fala seguinte, um envolvimento intenso entre o pai e o filho, não ficando o primeiro encarregado de proporcionar somente atividades de lazer, dividindo as responsabilidades no âmbito da educação com a sua ex-companheira.

durante a semana (...) ele [referindo-se ao filho] vai lá pra casa, a gente janta junto, conversa um pouco assim, eu quero saber sobre a aula, como é que ele tá indo na aula, essas coisas assim. E depois assim, a gente vai jogar vídeo game, ele assiste novela, ele gosta de assistir novela, daí depois ele volta pra casa. (P2)

Assim, verifica-se que a guarda compartilhada, neste caso, proporcionou além da manutenção da convivência, entre pais e filho, um equilíbrio das funções parentais, não havendo um genitor principal e um secundário. Neste sentido, Dolto (1989/2011) assinala que, ao se delegar a guarda a um dos genitores e estabelecer o papel do outro como visitante, é implicitamente dito à criança que um dos genitores é desvalorizado e falho. Além disso, Brito (2005) aponta que esta modalidade de custódia "assegura ao pai e à mãe seu lugar de educador junto à prole, rompendo com a tão criticada figura de 'pai de fim de semana"' (p.67).

Contudo, mesmo que a divisão de responsabilidades esteja prevista pela lei da guarda compartilhada, ainda assim, existe, em muitos casos, uma dissimetria nas funções exercidas por pais e mães. Contudo, parece que este desequilíbrio referente às obrigações para com os filhos, em relação aos participantes deste estudo, já se encontrava presente desde antes da separação.

Já era minha, já era minha [as responsabilidades em relação à filha] desde o início, sempre foi, então não mudou muita coisa, a diferença é que ele não tá mais ali, do lado, toda hora, sempre foi, a responsabilidade assim de tudo, sempre foi eu. (...) É que assim, no caso é guarda compartilhada, mas quem assume toda a responsabilidade sou eu. (M1)

As responsabilidades deles quando mais novos sempre fui eu né, o pai deles nunca fez nada, o pai deles nunca ajudou em nada. E hoje se acontecer alguma coisa, se de repente acontece alguma coisa, é eu que tenho que ir né. (M2)

Neste contexto, Wagner, Predebon, Mosmann e Verza (2005) salientam que mesmo sendo percebido atualmente um maior envolvimento por parte dos pais nas tarefas referentes aos cuidados com os filhos, estas mudanças parecem não ocorrer em todas as famílias. Observa-se, dessa forma, que estas transformações culturais acerca do desempenho das funções parentais são gradativas, sendo possível constatar, através das falas anteriores que ainda persiste socialmente a ideia tradicional da mãe como a figura encarregada de se ocupar dos filhos (Badinter, 1993). Já a figura paterna, muitas vezes, continua atrelada ao provimento material da família (Cúnico, 2011; Padilha 2008).

Ainda neste sentido, um dos entrevistados (P1), ao ser questionado sobre o motivo pelo qual não está tendo contato com os filhos, mesmo tendo estabelecido a guarda compartilhada, responde:

como eles não me procuram eu também não procuro eles, porque eles deveriam me procurar, se eles quisessem eles me procuravam(...) Eles sabem onde é que eu moro, sabem onde é que eu tô.(...) porque isso aí que tudo depende é deles né, não é tanto de $\operatorname{mim}(\ldots)(\mathrm{P} 1)$

É possível inferir, através do recorte anterior, que existe certa desresponsabilização por parte do pai, já que ele não busca o contato com os filhos na espera de que eles tomem a iniciativa. No entanto, o Estatuto 
da Criança e do Adolescente (ECA), sinaliza que "aos pais incumbe o dever de sustento, guarda e educação dos filhos menores, cabendo-lhes ainda, no interesse destes, a obrigação de cumprir e fazer cumprir as determinações judiciais" (Artigo 22), sendo que estas responsabilidades não deveriam se desfazer com a dissolução do casamento, como citado anteriormente.

\section{A entrada de um terceiro e a guarda compartilhada}

De acordo com Féres-Carneiro (1998), o grande número de separações está vinculado à grande importância dada ao casamento. A dissolução ocorre, de acordo com a autora, quando o parceiro não responde a expectativa do outro. Assim, o novo relacionamento surge como uma busca pela felicidade que não foi encontrada no casamento anterior, mas acredita-se ser possível deparar-se com ela quando o sujeito descobrir o par "correto" (D. Corso \& M. Corso, 2011).

A partir dos dados obtidos do Instituto Brasileiro de Geografia e Estatísica (IBGE), é possível verificar um acréscimo no número de recasamentos no ano de 2010 , sendo que os homens $(11,17 \%)$ recasaram-se mais que as mulheres $(7,98 \%)$. Estas estatísticas confirmam o que aponta Féres-Carneiro (1998), quando menciona que os homens estabelecem um novo relacionamento mais rapidamente que as mulheres, após a separação.

Neste cenário, o momento da entrada de um terceiro na família original poderá constituir para os filhos da relação anterior uma barreira para a concretização de sua fantasia de retorno da relação de seus pais (Soares, 2008). De acordo com a autora, a maneira como os pais conduzem este momento de transição da família irá produzir uma maior ou menor aceitação dos filhos. É possível observar, na fala seguinte, o estabelecimento de um bom relacionamento entre o novo parceiro da mãe e a filha.

Eu tenho esse outro relacionamento, é uma pessoa que tá sempre cuidando dela, tá sempre ajudando, conversando com ela e tudo (...). Então, ela já tá aceitando assim, porque ele tá querendo ajudar ela mesmo, ele dá carinho, tá sempre com ela, tentando suprir um pouco essa falta de pai que tem. (M1)

No modelo de família recomposto, de acordo com Féres-Carneiro (1998), a autoridade materna/ paterna passa a ser dividida com outros membros da família, conforme é expressa pelo relato da participante (M1). Além disso, Dolto (1989/2011) assinala que é saudável para a criança que diversos adultos do sexo masculino e feminino tomem conta dela. Ademais, é responsabilidade dos pais, de acordo com Bruno (2003), proporcionar aos filhos uma convivência com pessoas significativas de suas relações. No entanto, conforme citado anteriormente, a autoridade familiar é efeito da paternidade/maternidade, e não do matrimônio, cabendo aos pais o exercício dos deveres parentais.

No entanto, Dantas (2003) reconhece que com a nova união dos pais surge uma paternidade/maternidade social, ou seja, as funções parentais sendo exercidas pelos novos cônjuges. De acordo com a autora, neste momento o homem - genitor, que na maioria dos casos não reside com os filhos após a separação - depara-se com a seguinte questão: manter os vínculos com os filhos da relação anterior e/ou acolher os filhos da atual companheira.

Eu acho que me tirou muitas coisa, assim, sabe?! [referindo-se ao novo relacionamento] Até porque ela tem um filho também, e eu acho que ela podia entender um pouco mais o meu lado, sabe? Muitas vezes eu deixo de fazer algumas programações com meu filho assim, pra tá junto com o filho dela, entendeu?! E ela não sabe entender isso. (...) Eu acho que nesse sentido me atrapalha (...) (P2)

É possível verificar, através do relato anterior, que este pai (P2) diz sentir-se pressionado pela nova companheira, deixando de realizar atividades com seu filho, para estar junto ao filho dela. Neste viés, D. Corso e M. Corso (2011) apontam que a anulação dos filhos do relacionamento anterior, por parte do pai, pode funcionar como uma prova de devoção à nova companheira, em uma tentativa de anular a experiência anterior.

Ainda, pode existir uma insatisfação por parte das novas companheiras com seu atual parceiro, sobretudo quando este tem filhos pequenos que residem com suas mães, demandando, por parte do pai, uma relação com a ex-esposa (McGoldrick \& Carter, 1995). Através da fala seguinte é possível observar tal situação:

eu necessito conversar com ela [referindo-se a ex-companheira], não tem como eu não conservar com ela, então eu tenho que, às vezes, eu tenho 
que brigar com a minha namorada, digamos assim, pra mim poder conversar com ela (...). Ela tem muito ciúmes da minha ex, então ela tá sempre mexendo no meu celular, procurando mensagem, ligação, essas coisas assim, e querendo saber o que que eu conversei, aí acaba me estressando muito, sabe?! (P2)

Neste caso acima referido, a manutenção de um vínculo, mesmo que objetivando o cuidado com o filho em comum, causa na atual parceira sentimentos de ciúme, como se ainda houvesse um envolvimento amoroso entre o seu companheiro e a ex-companheira. Verifica-se, dessa forma, que para o novo sujeito que passa a fazer parte desta família também há uma dificuldade em diferenciar o relacionamento homem-mulher e o relacionamento pai-mãe, o que, por sua vez, poderá resultar em um obstáculo para a continuidade do exercício coparental.

Assim, pode-se perceber que existe um período até que as famílias recompostas se adaptem a esta nova configuração. De acordo com Soares (2008), neste processo de adaptação estão envolvidas diversas variáveis como "a idade dos filhos do primeiro casamento, o tempo decorrido entre o divórcio e o casamento, o grau de conflito que persiste entre os pais, a existência ou não de filhos de casamento anterior do novo cônjuge, entre outras." (p.93).

\section{Rede de apoio: o lugar da família extensa na guarda compartilhada}

Além dos filhos, após o término da relação conjugal existem inúmeras pessoas que precisam se reposicionar em relação a um casal que já não existe (D. Corso \& M. Corso, 2011; Dias \& Araújo, 2002), e estabelecer novos papéis a serem desempenhados.

Segundo Pereira e Arpini (2012), as novas configurações familiares podem contribuir para uma ampliação da rede de apoio, incluindo a família extensa e amigos próximos. Através da fala da participante (M1) pode-se perceber que a sua mãe, avó da criança, se tornou uma figura importante após a separação "Eu tenho a minha mãe próximo né. (...). Então, de manhã eu saio para trabalhar e minha mãe fica com ela [referindo-se à filha] (...)" (M1).
É possível notar, através do recorte anterior, que a avó se tornou personagem central na família, tendo atribuições e responsabilidades no momento em que a mãe não se encontra presente. Em pesquisa empreendida por Cardoso (2011), a autora verificou que não é incomum os avós ficarem responsáveis pelos netos. Em um total de doze avós participantes do estudo, sete declararam que possuem filhos que estão separados e que naquele momento estavam cuidando desses netos. Inferese, a partir disso, que ocorre uma aproximação entre avós e netos no momento de separação dos pais, talvez numa tentativa de proteção e cuidado. Também nesta pesquisa os participantes relataram a participação de membros da família extensa no cuidados com os filhos.

A minha mãe é aquela que não é avó, é avó-mãe, como eu digo. Porque ela agora ela tá com o meu já faz uns dois meses direto [hoje o filho reside com a avó materna] e tem mais outro netinho que tá sempre com ela, não, ela é uma xodózona do meu mais velho, que é o primeiro neto ao nenezinho, ao bisneto. Não, ela é bem legal com eles, correta. (M3)

Além deste envolvimento e apoio ser benéfico para os netos que estejam vivenciando a separação de seus pais, a relação entre estas gerações também beneficia os avós (Dias \& Araújo, 2002). No entanto, Cardoso (2011) assinala que pode haver uma sobrecarga nos avós quando acabam acolhendo em sua casa o filho e o neto após a separação, demandando muitas mudanças na vida deles, mesmo que por um período de transição.

Porém, não só os avós se tornam figuras importantes no apoio às famílias que vivenciaram a separação. Os tios também foram citados como pessoas que acabam exercendo outras funções nesta nova configuração "(...) tem a tia que tá me ajudando, a gente tem um convívio eu e ela, que ela tá procurando assim sabe, todos os meus irmãos tão sempre tentando apoiar ele [referindo-se ao filho] (...)" (M3).

Assim, se torna necessário ressaltar que o apoio oferecido pela família extensa, bem como pelos amigos e a escola, é fundamental nesse processo de separação conjugal. Em pesquisa realizada por Souza (2000), adolescentes que vivenciaram a separação de seus pais relataram ter sido importante 
ter alguém, fora do núcleo familiar, com quem falar sobre o momento que estavam vivenciando.

\section{Considerações finais}

Foi possível verificar, através deste estudo, que mesmo que a guarda compartilhada objetive a continuidade do exercício coparental, muitas são as mães que permanecem com a maioria das responsabilidades. Além disso, estas mães relataram que mesmo antes da separação, os deveres educativos já recaíam sobre elas. Neste sentido, constata-se a persistência da crença construída socialmente de que a mãe é a principal cuidadora.

No entanto, existem pais que, mesmo não residindo com os filhos, conseguem manter seus deveres e obrigações após a separação, quebrando com o estigma de "pai de fim de semana", rótulo este atribuído aos pais que realizam apenas atividades de lazer, sem se responsabilizar pela educação dos filhos. Observa-se que nestes casos, muitas vezes, os pais já eram presentes desde antes da separação, tendo a custódia conjunta oportunizado a continuidade desta responsabilidade parental.

Além disso, verificou-se que a presença do novo cônjuge do pai ou da mãe é outro aspecto que afeta o desempenho das funções parentais. Pode-se observar que em alguns casos o novo integrante da família surge como alguém para auxiliar e participar da educação dos filhos do atual parceiro(a). No entanto, há situações em que o (a) atual companheiro (a) não consegue diferenciar a relação entre pai e mãe e a relação amorosa de homem e mulher. Nestes casos, existe um obstáculo a ser superado para que os deveres coparentais, após o desenlace conjugal, continuem a ser exercidos. Também é importante frisar neste estudo a participação da família extensa após a separação. As avós, principais figuras citadas pelos participantes, passaram a exercer papel fundamental na vida dos filhos destes pais separados, com atribuições de cuidado quando os pais não estão presentes.

Por fim, ressalta-se a importância de outros estudos que abarquem as novas configurações familiares, para um melhor entendimento das relações construídas pós-divórcio. Além disso, a partir desta pesquisa, vê-se a necessidade de espaços que busquem o fortalecimento das relações parentais pós-divórcio, principalmente relativas aos pais, já que normalmente são eles que não residem com os filhos após a separação.

\section{Referências bibliográficas}

Alves, A. P. (2012). Reflexões sobre a guarda compartilhada: o olhar de pais que a vivenciam. Trabalho de Conclusão de Curso, Universidade Federal de Santa Maria, Santa Maria.

Badinter, E. (1985). Um amor conquistado - O mito do amor materno. Rio de Janeiro: Nova Fronteira.

Badinter, E. (1993). XY - Sobre a identidade masculina. Rio de Janeiro: Nova Fronteira.

Bardin, L. (1977). Análise de Conteúdo. Lisboa: Edições 70.

Bottoli, C. \& Arpini, D. M. (2011). 0 exercício da paternidade na separação conjugal. In F. P. Jaeger, C. S. Kruel \& A. C. Siqueira (Orgs.), Parentalidade e contemporaneidade: os desafios para a Psicologia (pp. 123-150). Santa Maria: Centro Universitário Franciscano.

Brandão, E. P. (2005) A interlocução com o direito à luz das práticas psicológicas em varas de família. In E. P. Brandão; \& H. S. Gonçalves. (Orgs.), Psicologia Jurídica no Brasil. 2 ed. (51-97). Rio de Janeiro: NAU Ed.

Brasil. (1988). Constituição Federativa do Brasil. (13º ed.). São Paulo: Saraiva.

Brasil. (1990). Lei n8.069. (13 jul. 1990). Dispõe sobre o Estatuto da Criança e do Adolescente e dá outras providências. Diário Oficial da União (Brasília, DF).

Brasil. (2002). Código Civil Brasileiro. (13º ed.). São Paulo: Saraiva.

Brasil. (2008). Lei $\mathrm{n}^{\circ}$ 11.698. (16 jun. 2008). Altera os arts. 15.83 e 1.584 da Lei n 10.406 , de 10 de janeiro de 2002 - Código Civil, para instituir e disciplinar a guarda compartilhada. Diário Oficial da União (Brasília, DF).

Brito, L. M. T. (2002). Impasses na condição da guarda e da visitação - o palco da discórdia. In R. C. Pereira (Org.), Família e cidadania - O novo CCB e a Vacatio Legis (433-448). Belo Horizonte: IBDFAM/ Del Rey. 
Brito, L. M. T. (2005). Guarda Compartilhada: um passaporte para a convivência familiar. In APASE Associação de pais e mães separados (Orgs.), Guarda Compartilhada: aspectos psicológicos e jurídicos. (pp. 53-69). Porto Alegre: Equilíbrio.

Bruno, D. D. (2003). Direito de Visita: direito de convivência. In G. C. Groeninga, \& R. C. Pereira (Orgs.), Direito de Família e Psicanálise: Rumo a uma nova epistemologia (311-324). Rio de Janeiro: Imago.

Cardoso, A. R. (2008). A escola diante da família pós-divórcio. In L. M. T. Brito, (org.), Famílias e Separações: Perspectivas da Psicologia Jurídica (pp. 49-79). Rio de Janeiro: EdUERJ.

Cardoso, A. R. (2011). Avós no século XXI - Mutações e rearranjos na família contemporânea. Curitiba: Juruá.

Conselho Federal de Psicologia (2000). Resolução 016/2000. Recuperado de <http://www.pol.org.br/ pol/export/sites/default/pol/legislacao/legislacaoDocumentos/resolucao2000_16.pdf>.

Conselho Nacional De Saúde (1996). Decreto $n^{\circ} 93933$. Resolução do Conselho Nacional de Saúde 196/96. Recuperado de <http:www.ufrgs.br/bioetica/ res19696.htm>.

Corso, D. L., \& Corso, M. (2011). A psicanálise na Terra do Nunca: ensaios sobre a fantasia. Porto Alegre: Penso.

Cúnico, S. D. (2011). O (não) exercício da paternidade: algumas reflexões. Trabalho de conclusão de curso, Curso de Psicologia, Universidade Federal de Santa Maria, Rio Grande do Sul, Brasil.

Dantas, C. R. T. (2003). O exercício da paternidade após a separação: um estudo sobre a construção e a manutenção do vínculo afetivo entre pais e filhos na família contemporânea. Dissertação de mestrado, Pontifícia Universidade Católica do Rio de Janeiro, Rio de Janeiro.

Dias, C. M. S. B., \& Araújo, M. R. G. L. (2002). Papel dos avós: apoio oferecido aos netos antes e após situações de separação/divórcio dos pais. Estudos de psicologia 7(1), 91-101.

Dolto, F. (2011). Quando os pais se separam ( $2^{\circ}$ ed.) Rio de Janeiro: Zahar.

Féres-Carneiro, T. (1998). Casamento contemporâneo: o difícil convívio da individualidade com a conjugalidade. Psicologia Reflexão e Crítica, 11, 379-394.
Grisard Filho, W. (2005). Guarda compartilhada: uma nova dimensão na convivência familiar. 0 discurso do judiciário. In APASE - Associação de pais e mães separados (Orgs.), Guarda Compartilhada: aspectos psicológicos e jurídicos. (73-87) Porto Alegre: Equilíbrio.

Grisard Filho, W. (2009). Guarda Compartilhada: um novo modelo de responsabilidade parental ( $4^{\circ} \mathrm{ed}$. rev., atual. e ampl.) São Paulo: Editora Revista dos Tribunais.

Instituto Brasileiro de Geografia e Estatística. (2010). Séries e estatísticas. Recuperado em 25 de outubro, 2012 de http://www.ibge.gov.br.

Madaleno, R. (2012). Guarda compartilhada. In D. S. Ibias (Org.), Família e seus desafios: reflexões pessoais e patrimoniais (114-135). Porto Alegre: IBDFAM/RS.

McGoldrick, M., \& Carter, B. (1995). Construindo uma família recasada. In B. Carter \& M. McGoldrick (Orgs.), As mudanças do ciclo de vida familiar: uma estrutura para a terapia de família (344-369). Porto Alegre: Artes Médicas.

Padilha, C. C. (2008). Quando o pai vira réu por alegação de abandono afetivo. In L. M. T. Brito (Org.), Famílias e Separações: Perspectivas da Psicologia Jurídica (187217). Rio de Janeiro: ED/UERJ

Pereira, R. C. (2005). Princípios norteadores para o direito de família. Belo Horizonte: Del Rey.

Pereira, R. C. (2011). Divórcio: teoria e prática. (3ª ed.) Rio de Janeiro: GZ Ed.

Pereira, C. R. R., \& Arpini, D. M. (2012). Os irmãos nas novas configurações familiares. Psicologia argumento 30(69) 275-285.

Ramos, P. P. C. (2005). A moderna visão da autoridade parental. In APASE - Associação de pais e mães separados (Orgs.), Guarda Compartilhada: aspectos psicológicos e jurídicos. (pp. 97-121) Porto Alegre: Equilíbrio.

Reis, E. F. (2010). Varas de família - um encontro entre Psicologia e Direito. Curitiba: Juruá.

Roudinesco, E. (2003). A família em desordem. Rio de Janeiro: Zahar.

Silva, E. L. (2005). Guarda de filhos: aspectos psicológicos. In APASE - Associação de pais e mães separados (Orgs.), Guarda Compartilhada: aspectos psicológicos e jurídicos. (pp. 13-32) Porto Alegre: Equilíbrio. 
Silva, M. R., \& Piccinini, C. A. (2007). Sentimentos sobre a paternidade e o envolvimento paterno: um estudo qualitativo. Estudos de Psicologia, 24(4), 561-573.

Simão, R. B. C. (2005). 0 abuso de direito no poder parental. In APASE - Associação de pais e mães separados (Orgs.), Guarda Compartilhada: aspectos psicológicos e jurídicos. (33-51) Porto Alegre: Equilíbrio.

Soares, L. C. E. C. (2008). A família com padrasto e/ou madrasta: um panorama. In L. M. T. Brito (Org.), Famílias e Separações: Perspectivas da Psicologia Jurídica (81112). Rio de Janeiro: ED/UERJ
Sousa, A. M. (2010). Síndrome da alienação parental - um novo tema dos juízos de família. São Paulo: Cortez.

Souza, R. M. (2000). Depois que papai e mamãe se separaram: um relato dos filhos. Psicologia: Teoria $e$ Pesquisa, 16(3), 203-211.

Turato, E. R. (2003). Tratado de metodologia da pesquisa clínico-qualitativa. Petrópolis: Vozes.

Wagner, A., Predebon, J., Mosmann, C., \&Verza, F. (2005). Compartilhar tarefas? Papéis e funções de pai e mãe na família contemporânea. Psicologia: Teoria $e$ Pesquisa, 21(2), 181-186. 